\title{
Bicornuate uterus and pregnancy a propos one case and review of the litterature
}

\author{
S. Mezane ${ }^{1,2, ~ *}$, M. Achenani ${ }^{1,2}$, Y. Benabdejalil ${ }^{1,2}$, M. Ziyadi ${ }^{1,2}$, R. Hafidi ${ }^{1,2}$, I. Hakimi ${ }^{1,2}$, \\ A. Babahabib ${ }^{1,2}$, M. Hassani ${ }^{1,2}$, J. Kaouach ${ }^{1,2}$, D. Moussaoui ${ }^{1,2}$, M. Dehayni ${ }^{1,2}$ \\ ${ }^{1}$ Department of Gynecology-Obstetric, Military Hospital Mohammed V, Rabat, Morocco \\ ${ }^{2}$ Faculty of Medicine and Pharmacy, University Mohammed V Souissi, Rabat, Morocco
}

\section{Email address:}

souadmid@hotmail.fr (S. Mezane)

\section{To cite this article:}

S. Mezane, M. Achenani, Y. Benabdejalil, M. Ziyadi, R. Hafidi, I. Hakimi, A. Babahabib, M. Hassani, J. Kaouach, D. Moussaoui, M. Dehayni. Bicornuate Uterus and Pregnancy a Propos One Case and Review of the Litterature. Journal of Gynecology and Obstetrics. Vol. 2, No. 3, 2014, pp. 42-45. doi: 10.11648/j.jgo.20140203.13

\begin{abstract}
Frequency of uterine malformations having an impact on reproduction is difficult to assess. Their detection requires specific exams (hysterosalpingography, hysteroscopy, laparoscopy). Spontaneous fertility can be altered depending on the type of uterine anomaly. All these anomalies can affect the evolution of the pregnancy: early fetal loss and late fetal loss, ectopic pregnancy, premature delivry, premature birth,vascular pathologies in pregnancy and fetal growth restriction. Ovarian function is not changed. Bicornuate uterus is the most common uterine malformations representing about half of the anomalies of the uterus. Surgery, including endoscopic allows precise diagnosis, assessment of prognosis and treatment improving the chances of conception and evolution of pregnancies. The occurrence of such a pregnancy is a dangerous situation that can lead to maternal death, but early diagnosis and good following can carry pregnancies to term. Ultrasound screening should allowed the identification of such cases in order to take preventive measures. We report a case of a bicornualunicervical uterus in a pregnancy at 38 weeks of gestation diagnosed during ultrasound first trimester of pregnancy.
\end{abstract}

Keywords: Bicorrnuate Uterus, Uterine Malformation, Pregnancy

\section{Introduction}

Uterine malformations are relatively common and represent 3 to $4 \%$ of the female population[1][2]. Pregnancies occurring in a malformed uterus are relatively rare. Many of them are asymptomatic and the diagnosis is made fortuitously during an examination for any other purpose. So it is not unusual to made the diagnosis of bicornuate uterus in a first pregnancy check or to discover it during a vaginal delivery. Fortunately, many of them are asymptomatic. It is important to consider this diagnosis in all patients with a history of recurrent miscarriage, late miscarriages or in the adolescent who consults for primary amenorrhea, dysmenorrhea, dyspareunia or in patients followed in reproductive medicine [2].

\section{Clinical Case}

Mrs T.N, 29 years old primigravida woman, with no medical and family history. Her pregnancy was followed in our department since 10 weeks of gestation. An ultrasound made in the first trimester of pregnancy showed a bicornuateunicervical uterus. The follow-up was normal. A $\mathrm{C}$-section was programmed at 38 weeks of gestation. The obstetric examination at 38 weeks of gestation revealed a fundal height at $32 \mathrm{~cm}$, fetal active movements were well perceived by the patient. There was no palpable uterine contraction and the fetal heart sounds correctly. In the vaginal touch, the cervix were posterior, long with cephalic presentation. Ultrasound showed an evolutionary pregnancy in cephalic presentation, fetal biometry were between 10th and 25th percentile; The estimation of fetal weight was $3100 \mathrm{~g}$ and the quantity of amniotic fluid was normal. The $\mathrm{C}$-section was carried out under spinal anesthesia allowing the extraction of a newborn baby boy male Apgar 10/10 at 1, 5 and 10 minutes of life, weighing $2900 \mathrm{~g}$. Examination of the newborn was unremarkable. The post-operative course was uneventful for the mother. The intervention confirmed the appearance unicervical 
uterus bicornis (fig 1). The diagnosis of this type of anomaly can be done relatively simply in early pregnancy at a stage where we still visualize the uterus and its contents fairly easily. It becomes more difficult when the pregnancy is more advanced, but still possible if one is attentive to the structure of the myometrium around the gestational sacs.

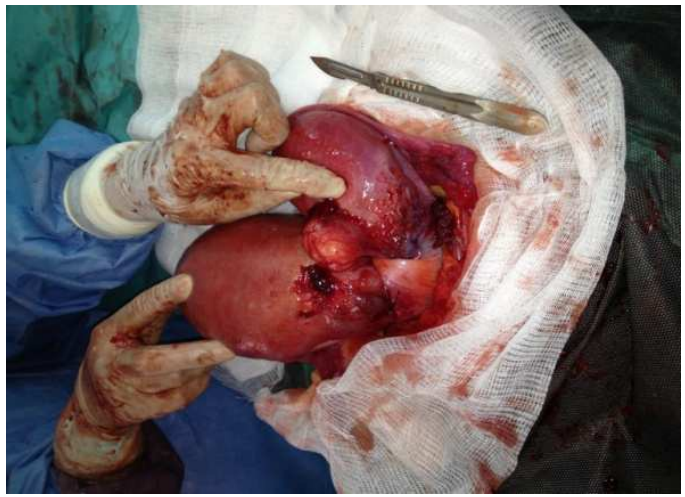

Figure 1: Bicornual uterus during the C-section.

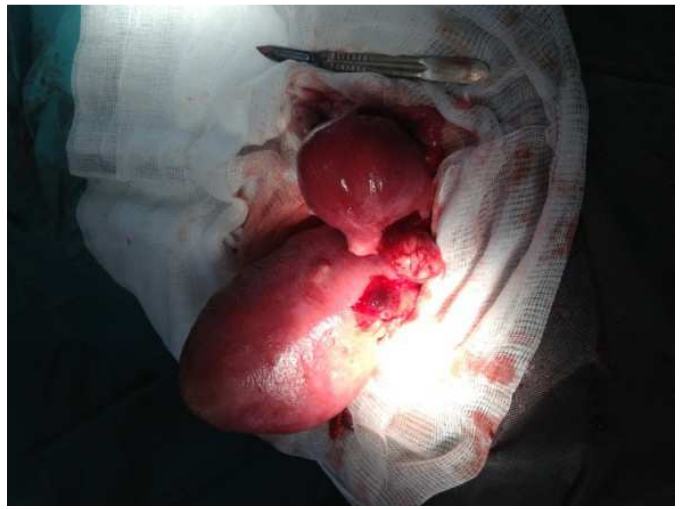

Figure 2: Bicornual uterus during the C-section.

\section{Discussion}

\subsection{Organogenesis [4]}

The differenciation of the different parts of the female genital tract starts from the $7^{\text {th }}$ week of development. In the absence of anti- Müllerian hormone, the Wolffian ducts regress and Mullerian ducts will develop. This development consists of three phases:

$>$ Migration Müllerian ducts to the urogenital sinus (6th to 9 th week).

$>$ Apposition of the lower third of the Müllerian ducts form the uterus and the upper two thirds of the vagina ( 9th-13th week)

$>$ Resorption of the inter- Müllerian partition (13th to 17 th week).

Most uterine malformations can be explained by a defect or developmental arrest in these three phases. The absence of migration or incomplete caudal migration of Müllerian ducts to the urogenital sinus will be responsible for atresia and / or complete or not uterine aplasia. A failure of fusion of the Müllerian ducts leads to duplication uterus (uterus didelphys, uterus bicornis ).A lack of resorption of the inter- Müllerian partition leads to a partitioned uterus.

Other important points: The upper two thirds of the vagina with the same embryological origin as the uterus, uterine malformations are often associated with high vaginal malformations. A relatively constant feature is the association of abnormalities of the genital and urinary system, embryogenesis of these two systems is closely linked. The development of the ovaries is not linked to channels Müller, morphology and ovarian function are usually normal in utero-vaginal malformations.Uterine malformations are not associated with a chromosome abnormality or abnormal sexual differentiation.

\subsection{Pregnancy and Bicornuate Uterus}

The incidence of congenital uterine anomalies in a fertile population is $3.2 \%, 90 \%$ of uterine septum and $5 \%$ of bicornuate uterus or didelphes uterus [5]. A large casecontrol study by a Spanish collaborative study of congenital malformations viewed at 26945 malformed children and assessed the frequency of congenital anomalies in offspring of mothers with bicornuate uterus. This study showed that the risk of congenital malformations was found four times higher among mothers with bicornuate uterus [6]. Another retrospective longitudinal study abnormalities demonstrated live birth rate of $62.5 \%$ in case of bicornuate uterus but arly miscarriages and premature labor were more frequent [7]. The bicornuate uterus complicated pregnancy, but does not prevent it. It is often that the pregnancy itself which reveals the malformation, as it can cause repeated abortions. The diagnosis is confirmed by ultrasound. Although this is not an obstacle to the design, this anomaly may hinder a good location in the uterine wall. The risk of miscarriage increases about $30 \%$. For others, uterine malformation will cause risk pregnancy and obstetric complications [3]. If congenital uterine malformations are present in 3-4 \% of the fertile female population and / or infertile, the frequency rises to $5-10 \%$ for women looking for recurrent miscarriage and $25 \%$ in women with false late layers or premature delivery. [3] The problem with these patients is not the design, but to complete the pregnancy. Several factors explain this: uterine malformations are associated with uterine cavity smaller, less efficient muscles, inability to distend ,myometrial and cervical dysfunction, inadequate vascularization and a poorly developed endometrium. These abnormalities contribute at a rate of recurrent miscarriage premature delivry, fetal growth restriction and higher caesarean; with an increased risk of uterine rupture especially if pregnancy in rudimentary horn, if the embryo hangs in the smallest room uterus, the risk of not wearing a pregnancy to term are unfortunately increased, because the fetus does not have enough room to grow. [3]

\subsection{Delivry and Bicornuate Uterus}

In general, before the birth, the baby turns and positioned 
upside down, allowing him to use the largest square of the uterus to its body and legs. However, in the case of a bicornuate uterus, the baby may feel more comfortable head up, positioning the widest part of his body into the maternal pelvis. That is why the rate of presentation baby " in office" is higher in this case. This malformation of the uterus can also cause risk of early placenta, the latter being sometimes less firmly implanted in the uterus for lack of space. Baby's health may be compromised. Some obstetricians recommend a cesarean section at 37 weeks of gestation, but many women can also benefit from a natural childbirth.[3] Have children with a bicornuate uterus is possible. However, it requires patienc, perseverance and a serious medical monitoring.

\subsection{Treatment of Bicornuate Uterus}

\subsubsection{Before Pregnancy}

The management of uterine malformations before pregnancy includes surgical treatment as long as its indicated and possible. For bicornuatebicervical uterus, reunification surgery with two hemi-uterus was described by Strassmann in 1952; It showed no real benefit. [8]. It should be reserved only for patients with bad obstetrical prognosis and whose historyreveals several late miscarriages. Septateuterus are the only uterine malformations which surgical treatment is relatively simple. It consists of a resection of the septum by hysteroscopy. This treatment is indicated in symptomatic patients who had obstetric complications in their history. [9], [10], [11]. Given the simplicity of this surgery and low morbidity, some authors recommend to treat $\mathrm{t}$ this malformation from his diagnosis in order to reduce the risk of late miscarriages.

\subsubsection{During Pregnancy}

When the diagnosis of uterine malformation is laid in early pregnancy, treatment will only be preventive (rest, lung maturation, ultrasound monitoring of fetal growth and cervical competence). [13] Cervical cerclage should be offered in cases of cervical incompetence proved, what is observed in $25-30 \%$ of cases of uterine malformations [14], [15], [16]. The role of cervical cerclage is not clear in the prevention of preterm birth, except when incompetent cervix is documented by ultrasound or hysterosalpingography or in case of history of previous preterm deliveries. Otherwise, bicornuate uterus which is seen during cesarean section with term pregnancies or near term without cervical cerclage is rare. This is an effective procedure in the bicornuate uterus for the prevention of preterm birth, but it has no effect on the outcome of pregnancy in utero - Sarque [17]. From these various studies, we can conclude that uterine malformations result essentially obstetric complications such as spontaneous abortion and premature delivery outside the arched shape that would have no impact. There would be no direct relationship between infertility and malformation, although resection of a uterine septum improves the reproductive performance of infertile patients and a bicornuate uterus can carry a pregnancy to term.

\section{Conclusion}

Congenital uterine malformations are relatively common and often asymptomatic. Their exact incidence is difficult to assess. They can occur in the form of gynecological disorders or affect reproduction. Each clinician must seek a malformation in utero- vaginal presence of primary amenorrhea, abdominal pain, recurrent miscarriages and some adverse obstetrical outcomes. The psychological care may be necessary for some patients. It should be recalled that in the diagnosis of uterine malformation, urinary tract imaging should be performed because of frequent associated anomalies. A bicornuate uterus does not always lead to complications but it can carry a pregnancy to term. It is necessary to strengthen the capacity to establish a prenatal diagnosis to ensure proper care. This kind of malformation is very rare but it is important to make the ultrasound diagnosis in order to manage the situation proactively and allow the extraction of the fetus in good condition before any complication.

\section{References}

[1] Nahum GG. Uterine anomalies. How common are they, and what is their distribution among subtypes ? J Reprod Med 1998;43:877-87.

[2] Raga F, Bauset C, Remohi J, et al. Reproductive impact of congenital Mullerian anomalies. Hum Reprod 1997;12:2277-81.

[3] revue.medhyg.ch/article.php3?sid=33521 Rédigé par Odile Penet on Fév, 092010

[4] Poncelet C, Aissaoui F. Malformations utérines et reproduction. GynecolObstetFertil 2007;35:821-5.

[5] Troiano RN, McCarthy SM. Mullerian duct anomalies : Imaging and clinical issues. Radiology 2004;233:19-34.

[6] The American Fertility Society classifications of adnexal adhesions, distal tubal occlusion, tubal occlusion secondary to tubal ligation, tubal pregnancies, mullerian anomalies and intrauterine adhesions. FertilSteril 1988; 49:944-55.

[7] Deutch TD, Abuhamad AZ. The role of 3-dimensional ultrasonography and magnetic resonance imaging in the diagnosis of mullerian duct anomalies : A review of the literature. J Ultrasound Med 2008;27: 413-23.

[8] Strassmann EO. Plastic unification of double uterus ; A study of 123 collected and five personal cases. Am J ObstetGynecol 1952;64:25-37.

[9] Woelfer B, Salim R, Banerjee S, et al. Reproductive outcomes in women with congenital uterine anomalies detected by three-dimensional ultrasound screening. ObstetGynecol 2001;98:1099-103.

[10] Heinonen PK. Complete septate uterus with longitudinal vaginal septum. FertilSteril 2006;85:700-5. 
[11] Lourdel E, Cabry-Goubet R, Merviel P, et al. Utérus cloisonné : place de l'hystéroplastiehystéroscopique. GynecolObstetFertil 2007;35:811-8.

[12] Canis M, Wattiez A, Pouly JL, et al. Laparoscopic management of unicornuate uterus with rudimentary horn and unilateral extensive endometriosis : Case report. Hum Reprod 1990;5:819-20.

[13] Airoldi J, Berghella V, Sehdev H, Ludmir J. Transvaginal ultrasonography of the cervix to predict preterm birth in women with uterine anomalies. ObstetGynecol 2005;106:553-6.
[14] Acien P. Reproductive performance of women with uterine malformations. Hum Reprod 1993;8:122-6.

[15] Golan A, Langer R, Neuman M, et al. Obstetric outcome in women with congenital uterine malformations. J Reprod Med 1992;37:233-6.

[16] Golan A, Langer R, Wexler S, et al. Cervical cerclage- its role in the pregnant anomalous uterus. Int $\mathrm{J}$ Fertil 1990;35:164-70.

[17] Reichman D, Laufer MR, Robinson BK. Pregnancy outcomes in unicornuate uteri: a review. FertilSteril. 2009;91(5):1886-94. [PubMed] 